\title{
Remote CMR 4D Flow Quantification of Pulmonary Flow
}

\author{
Raluca G Saru*, Kevin Wanambiro', Albert Hsiao², Laurens E Swart', Sara Boccalini', Mika Vogel', Ricardo Budde”, \\ Shreyas Vasanawala ${ }^{3}$, Jolien Roos-Hesselink', Koen Nieman ${ }^{1}$ \\ From 19th Annual SCMR Scientific Sessions \\ Los Angeles, CA, USA. 27-30 January 2016
}

\section{Background}

4D MR flow has shown to have advantages over standard cardiac magnetic resonance (CMR), offering both anatomical and functional information in just a single acquisition. Pulmonary stenosis and pulmonary regurgitation are common problems in follow-up of patients with congenital heart disease.

In this study we tested flow quantification at the level of the pulmonary valve (forward and backward flow, regurgitation fraction and peak systolic velocity) using a cloudbased software platform fully integrated with correction for eddy currents, Maxwell phase effects and gradient field non-linearity, visualization of the flow and anatomy, and flow quantification. Standard planar phase contrast CMR was used as a reference.

\section{Methods}

Between July 2014 and April 2015, we prospectively included 50 consecutive adult patients planned for CMR with a clinical indication for flow measurement at the level of pulmonary valve and contrast administration. The 4D flow raw data sets were uploaded to a dedicated webbased software application (Arterys Inc., San Francisco, CA, USA).

Images were reconstructed in 20 cardiac temporal phases separately with a compressed sensing algorithm. The forward and backward flow, the regurgitant fraction and the peak systolic velocity measured by CMR 4D flow were compared against planar CMR measurements. To assess the usefulness of corrections for Maxwell phase effects, encoding errors and eddy-currents, these corrections have been turned off and flow calculations were redone and compared against standard CMR measurements.

\section{Results}

The mean forward flow over the pulmonary valve was $92( \pm 30) \mathrm{ml} /$ beat for CMR 4D flow and $86( \pm 30) \mathrm{ml} /$ beat for planar CMR. The Pearson's correlations between CMR 4D flow and CMR were 0.87, 0.95 and 0.85 for forward flow, backward flow and regurgitant fraction respectively. If the corrections for Maxwell phase effects, encoding errors and eddy-currents were not activated for 4D CMR Flow, the correlation for the forward flow was 0.275 .

To identify clinically relevant moderate and severe regurgitation, we have used a threshold of $20 \%$ of regurgitant fraction. This resulted in sensitivity of $83 \%$ (95\%CI: $36 \%-100 \%$ ), specificity of $98 \%$ (95\%CI: $88 \%-100 \%$ ), positive predictive value of $83 \%$ ( $95 \% \mathrm{CI}: 36 \%-100 \%)$, negative predictive value of $98 \%$ (95\%CI: $88 \%-100 \%)$ and accuracy of $96 \%$ for CMR 4D flow imaging.

The mean peak systolic velocity measured with CMR 4D flow was $123( \pm 55) \mathrm{cm} / \mathrm{sec}$ and $96( \pm 51) \mathrm{cm} / \mathrm{sec}$ measured with planar CMR and the correlation between the two modalities was 0.78 .

\section{Conclusions}

In this study we showed that pulmonary regurgitation can be quantified accurately using CMR $4 \mathrm{D}$ flow imaging analysed using a cloud based software. Corrections for Maxwell phase effects, encoding errors and eddy-currents improves overall accuracy of the technique enabling standardized offsite evaluation of CMR examinations.

\footnotetext{
Authors' details

${ }^{1}$ Radiology and Cardiology, Erasmus MC, Rotterdam, Netherlands. ${ }^{2}$ University of california, San Diego, CA, USA. ${ }^{3}$ Stanford University, Palo Alto, CA, USA.
} 
- Convenient online submission

- Thorough peer review

- No space constraints or color figure charges

- Immediate publication on acceptance

- Inclusion in PubMed, CAS, Scopus and Google Scholar

- Research which is freely available for redistribution 